\title{
Overexpression of MicroRNA-9 inhibits proliferation of human breast cancer cells by targeting STAT3
}

\author{
Yan Zhang*, Guangquan Dai \\ Department of Breast Surgery, Affiliated Weihai Second Municipal Hospital of Qingdao University, Weihai264200, PR China \\ *For correspondence: Email: ZielinskiCanel@yahoo.com; Tel: 0086-06315271075

\begin{abstract}
Purpose: To study the role and therapeutic potential of miR-9 in the treatment of breast cancer. Methods: The expression of miR-9 was evaluated in breast cancer cell lines using quantitative real-time polymerase chain reaction (qRT-PCR). Proliferation was determined by 3-(4,5-dimethylthiazol-2-yl)-2,5diphenyltetrazolium bromide (MTT) assay, while cell migration was assessed by wound healing assay. Transfections were performed with Lipofectamine 2000 reagent. Overexpression of miR-9 was performed by transfecting breast cancer cells with miR-9 mimics, and suppression of STAT3 was done with Si-RNA construct. Target identification was carried out using target scan, while protein expression was determined with immunoblotting.

Results: The results revealed that miR-9 was significantly $(p<0.05)$ downregulated in the breast cancer cell lines. Overexpression of miR-9 significantly $(p<0.05)$ inhibited the proliferation of the breast cancer cells by initiation of apoptosis and cell cycle arrest. In addition, MiR-9 overexpression inhibited the migration of the breast cancer cells. TargetScan analysis showed that STAT3 was the potential target of miR-9: it was significantly downregulated in breast cancer cells overexpressing miR-9. Silencing of STAT3 exerted inhibitory effects on the proliferation and migration of breast cancer cells similar to that of miR-9 overexpression.

Conclusion: MiR-9 regulates the proliferation of human breast cancer by targeting STAT3. Hence, miR-9 can be potentially applied as a therapeutic agent for the management of breast cancer.
\end{abstract}

Keywords: Breast cancer, MicroRNA-9, STAT3, Apoptosis, Bioinformatic analysis

\begin{abstract}
This is an Open Access article that uses a funding model which does not charge readers or their institutions for access and distributed under the terms of the Creative Commons Attribution License (http://creativecommons.org/licenses/by/4.0) and the Budapest Open Access Initiative (http://www.budapestopenaccessinitiative.org/read), which permit unrestricted use, distribution, and reproduction in any medium, provided the original work is properly credited.
\end{abstract}

Tropical Journal of Pharmaceutical Research is indexed by Science Citation Index (SciSearch), Scopus, International Pharmaceutical Abstract, Chemical Abstracts, Embase, Index Copernicus, EBSCO, African Index Medicus, JournalSeek, Journal Citation Reports/Science Edition, Directory of Open Access Journals (DOAJ), African Journal Online, Bioline International, Open-J-Gate and Pharmacy Abstracts

\section{INTRODUCTION}

Breast cancer is one of the prevalent cancers among woman, and it causes considerable mortality throughout the world [1]. It is the most prevalent cause of death in women, with about half million deaths annually worldwide [2]. It has been reported that breast cancer constitutes about $14 \%$ of all the cancer-related deaths in women, and its incidence is still on the still increase [3]. The main obstacles to the treatment of breast cancer include unavailability of consistent biomarkers and therapeutic targets/agents.

Due to the functions of microRNA (miRNAs) in a wide array of biological processes, they are believed to act as targets for anticancer drugs 
[4]. The miRNAs do not code for any protein and are generally very short RNA molecules consisting of about 20 nucleotides [5]. They have been shown to control a number of processes, including cell division [6]. A number of studies have reported that miRNAs are involved in cancer development $[7,8]$. This is mainly due to altered expressions of miRNAs in cancerous tissues [9]. In particular, MiR-9 has been reported to play a role in the development and progression of several types of cancers. For instance, miR-9 regulates the metastasis of oesophageal cancer cells [10]. Similarly, it has been found that suppression of miR-9 causes activation of JAK/STAT pathway in HeLa cancer cells [11].

Nonetheless, the role of miR-9 in breast cancer has not been extensively studied. In the present study, the therapeutic potential of miR-9 in breast cancer was investigated.

\section{EXPERIMENTAL}

\section{Cell lines and culture conditions}

Breast cancer cell lines (MCF7, CAMA-1, SKBR-3, AU-565, BT-20, BT-483, BT-549) and a non-cancerous breast cell line (CL-S1) were obtained from American Type Culture Collection. The cell lines were maintained in Dulbecco's Modified Eagle's Medium (DMEM) containing fetal bovine serum albumin (10\% bovine serum, penicillin and streptomycin), and glutamine (2 $\mathrm{mM})$. The cells were grown in a $\mathrm{CO}_{2}$ incubator at $37^{\circ} \mathrm{C}$ and $98 \%$ humidity.

\section{RNA isolation and quantitative RT-PCR}

The RNA was isolated from the gastric cancer tissues and cell lines by Trizol reagent and then transcribed into cDNA using RevertAid cDNA synthesis kit. The expressions of miR-19a and CLU-5 were determined by qRT-PCR using Taq PCR Master Mix Kit (Qiagen) according to the guidelines of the manufacturer.

\section{Transfections}

The SK-BR-3 cells were transfected at $80 \%$ confluence with miR-NC and miR-9 mimics (10 pmol, Shanghai GenePharma) and Si-NC or SiSTAT3 using Lipofectamine 2000 (Invitrogen) as per manufacturer's guidelines.

\section{Anti-proliferative and colony formation assays}

Breast cancer cell proliferation was assessed with MTT assay as described previously by
Mosmann [12]. Oral cancer cells were transfected and the proliferation was determined by reading absorbance at $570 \mathrm{~nm}$ at varied time intervals $(0,24,48,72,96 \mathrm{~h})$. For assessment of the colony formation potential of the transfected SK-BR-3 cells, the growing cells were harvested at exponential phase and subjected to counting in a hemocytometer. The platting of the transfected cells was carried out at 200 cells/well. The plates were then kept at $37^{\circ} \mathrm{C}$ for 6 days. After incubating the cells for about six days, they were washed with PBS and fixed with methanol. They were then stained with crystal violet and examined by microscopy.

\section{Apoptosis assay}

The apoptosis-inducing effects of miR-9 were determined by DAPI staining as described previously [13]. In brief, the oral cancer cells (0.6 $\times 10^{6}$ ) were grown in 6-well plates. Following 12 $h$ of incubation, the cells were subjected to transfection with miR-9. The cell cultures were then centrifuged and the pellets were washed with PBS. Thereafter, the cells were DAPIstained, centrifuged and the PBS was washed off. Finally, the nuclear morphology of the stained cells was examined by fluorescence microscopy. The percentage of the apoptotic cells was estimated by Annexin V/PI staining [14].

\section{Cell cycle analysis}

Approximately $1 \times 10^{5}$ SK-BR-3 cells in each well of 6-well plates were transfected with miR-NC or miR-9 mimics and incubated at $37^{\circ} \mathrm{C}$ for $24 \mathrm{~h}$. The distribution of the SK-BR-3 cells in various cell cycle phases was determined by flow cytometry as described previously [15].

\section{Wound healing assay}

The potential of the SK-BR-3 cells transfected to migrate was investigated with wound healing assay. The cells at the density of $5 \times 10^{4}$ cells per well were cultured in 96-well plates. The plates were then subjected to incubation at $37^{\circ} \mathrm{C}$ for 24 to allow for adherence. A wound was scratched on the plate with the help of sterile pipette tip. The cells were then washed with PBS, monitored after $48 \mathrm{~h}$ interval and photographed.

\section{Western blot assay}

After lysis of the breast cancer cells in RIPA lysis buffer, the protein content of the each lysate was estimated by BCA assay, and the samples were thereafter subjected to separation using SDSPAGE. After the electrophoresis, the gels were 
transferred to nitrocellulose membranes and treated with primary antibody at $4{ }^{\circ} \mathrm{C}$ for $24 \mathrm{~h}$. Subsequently, the membranes were incubated with horseradish peroxidase (HRP)-conjugated secondary antibody $(1: 1000)$ for $50 \mathrm{~min}$ at $25^{\circ} \mathrm{C}$, after which enhanced chemiluminescence was used to visualise the protein bands.

\section{Statistical analysis}

All experiments were done in triplicate and the data presented as mean \pm SD. Student's t-test, with the aid of GraphPad Prism 7 was used for the statistical analysis. Statistical difference was set at $p<0.05$.

\section{RESULTS}

\section{MiR-9 downregulated human breast cancer cell lines}

The expression of miR-9 was studied in six different breast cancer cell lines and one normal cell line by quantitative RT-PCR. The results showed that the expression of miR-9 was significantly downregulated in all the breast cancer cell lines (Figure $1 \mathrm{~A}$ ). The expression of miR-9 was about 9-fold lower in the breast cancer cell lines than in the control, noncancerous CSL- 1 cells. The lowest expression was observed in the SK-BR-3 breast cancer cell line.

\section{Overexpression of miR-9 inhibited proliferation of SK-BR-3 breast cancer cells}

To study the role of miR-9 in the breast cancer cells, miR- 9 was overexpressed by transfection of the breast cancer cells with miR-NC or miR- 9 mimics. The results showed that overexpression of miR-9 in the SK-BR-3breast cancer cells inhibited their proliferation in a time-dependent manner (Figure 1 B). Furthermore, overexpression of miR-9 caused significant inhibition of colony formation in the SK-BR-3 breast cancer cells (Figure $1 \mathrm{C}$ ).

Results from DAPI and annexin V/PI staining revealed that overexpression of miR-9 triggered apoptosis in the SK-BR-3 breast cancer cells (Figure 2 A). Annexin V/PI test showed that the proportion of cells undergoing apoptosis was $28.3 \%$, relative to $3.2 \%$ apoptotic cells in the miR-NC-transfected cells (Figure $2 \mathrm{~B}$ ). It was observed that miR-9 overexpression resulted in the accumulation of the SK-BR-3 breast cancer cells in sub-G1 phase of the cell cycle, indicating sub-G1 cell cycle arrest (Figure $2 \mathrm{C}$ ).

\section{Overexpression of miR-9 suppressed migration of SK-BR-3 breast cancer cells}

The effect of overexpression of miR-9 was also investigated on the migration of the breast cancer cells using wound healing assay. The results showed that miR-9 overexpression caused significant decrease in the migration and breast cancer cells, when compared to the cells transfected with miR-NC (Figure 3).

\section{MiR-9 targeted STAT3 in the SK-BR-3 breast cancer cells}

TargetScan analysis revealed that STAT3 was the potential target of miR-9 (Figure 4A). Therefore the expressions of STAT3 in all the breast cancer and the normal cell lines were investigated. The results revealed that STAT3 was significantly overexpressed in all the breast cancer cell lines (Figure 4B). However, miR-9 overexpression caused significant downregulation of STAT3 in SK-BR-3 breast cancer cells, which further confirmed that STAT3 was the target of miR-9 (Figure 4C). Silencing of STAT3 also inhibited the proliferation of SK-BR-3 breast cancer cells (Figure 4D). The results of colony formation assay revealed that silencing of STAT3 suppressed the colony formation potential of the SK-BR-3 breast cancer cells (Figure 5), while results from wound healing assay revealed that STAT3 silencing inhibited the migration of the breast cancer cells (Figure $6)$.

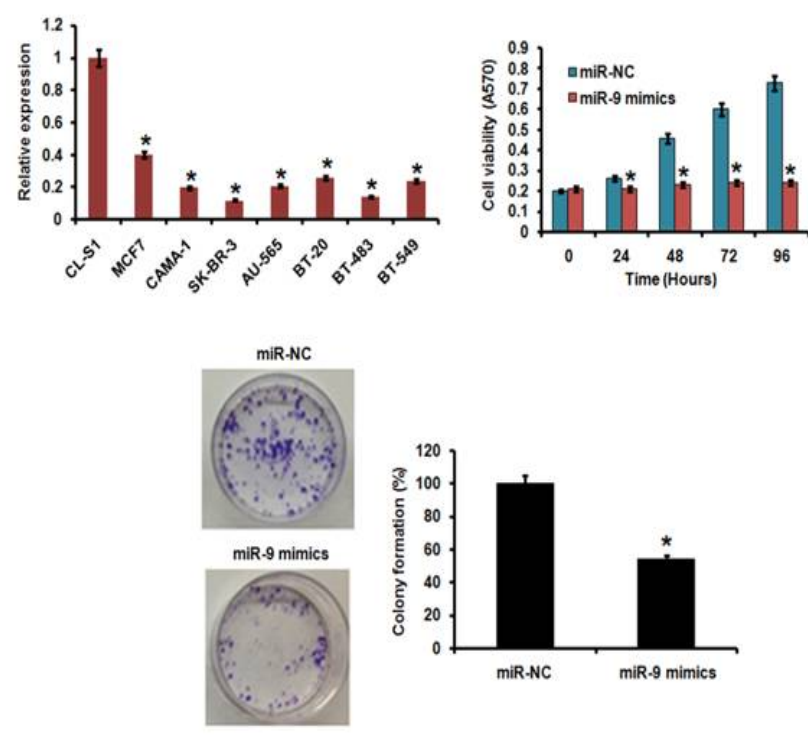

Figure 1: (A) Expression of miR-9 in human breast cancer cell lines and one normal breast cancer cell line. (B): Effect of miR-9 overexpression on SK-BR-3 cancer cell proliferation. (C): Colony formation. The experiments were carried out in three biological replicates, and data are expressed as mean $\pm \mathrm{SD}$. * $p$ $<0.05$ 
A

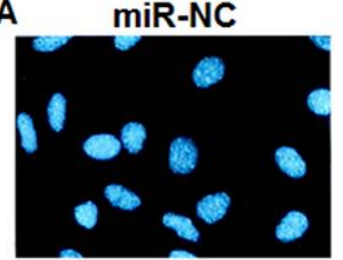

B
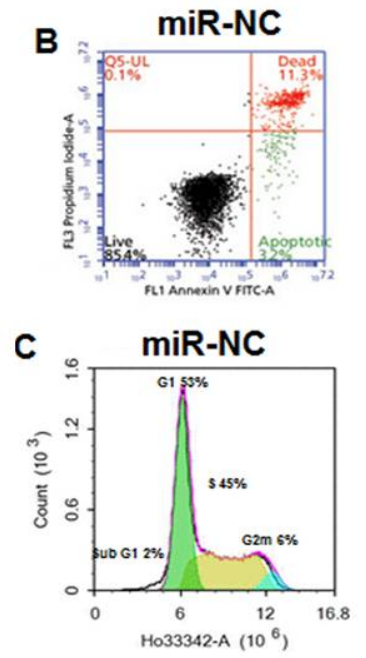

miR-9 mimics

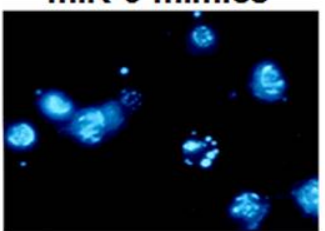

miR-9 mimics

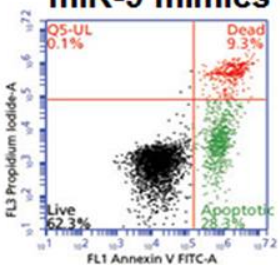

miR-9 mimics

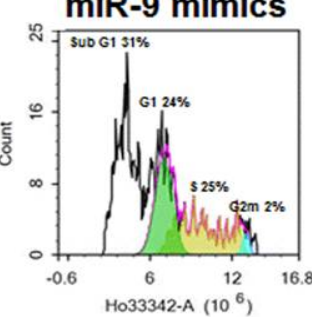

Figure 2: Apoptosis in SK-BR-3 breast cancer cells was triggered by miR-9 overexpression, as revealed by (A) DAPI staining, and (B) Annexin V/PI staining. (C): Overexpression of miR-9 triggered sub-G1 cell cycle arrest in SK-BR-3 breast cancer cells
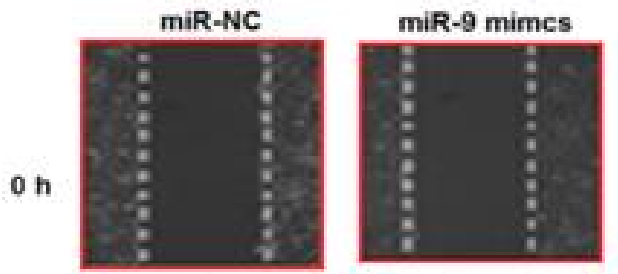

$48 \mathrm{~h}$
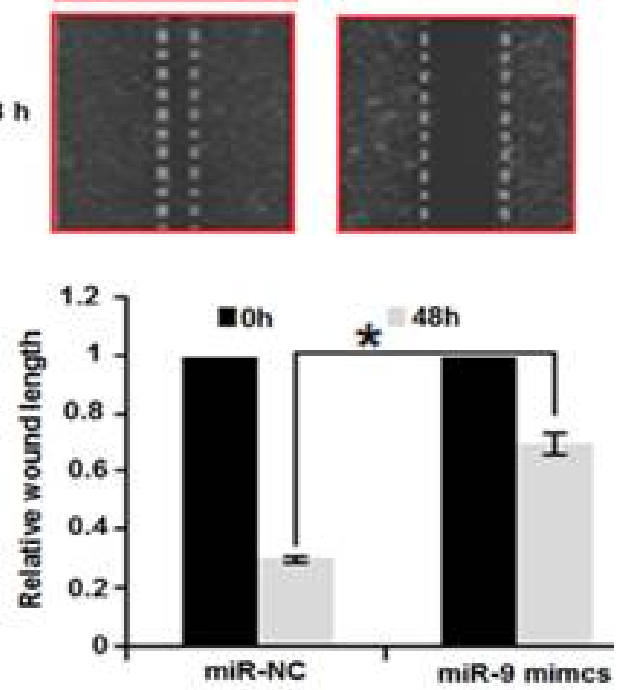

Figure 3: Inhibition of the migration of the SK-BR-3 breast cancer cells by overexpression of miR-9.The experiments were carried out in three biological replicates, and data are expressed as mean \pm SD. * $p$ $<0.05)$
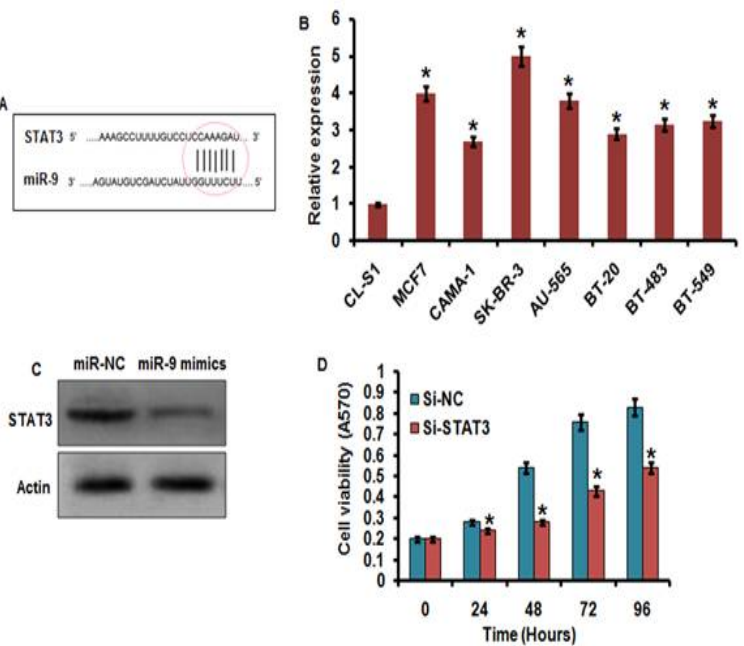

Figure 4: (A) TargetScan analysis showing that miR-9 targeted STAT3 (B) expression of STAT3 in breast cancer cells, as indicated by qRT-PCR assays. (C): Expression of STAT3 in miR-NC and miR-9 mimicstransfected SK-BR-3 breast cancer cells. (D): Effect of STAT3 suppression on SK-BR-3 breast cancer cell proliferation. The experiments were carried out in three biological replicates, and the results are expressed as mean \pm SD $(p<0.05)$
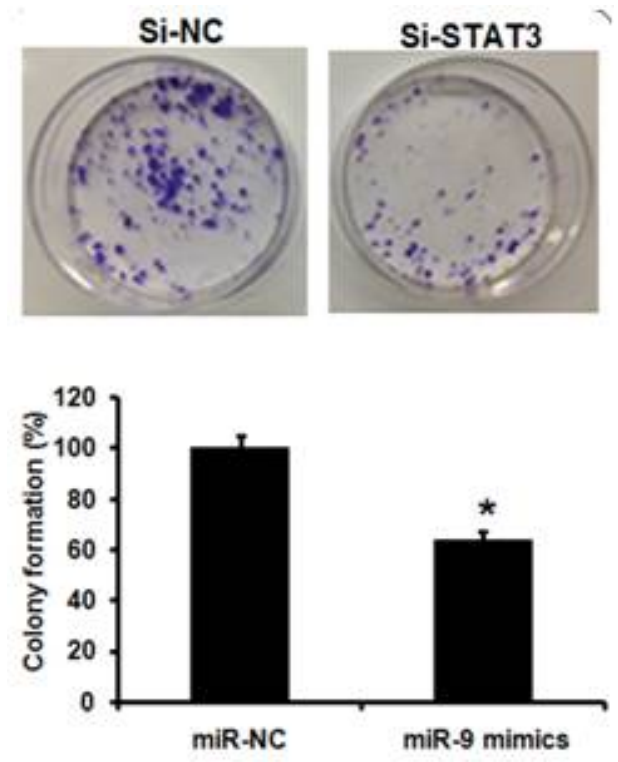

Figure 5: Effect of STAT3 suppression on colony formation of SK-BR-3 breast cancer cells. The experiments were carried in triplicate, and the data are expressed as mean \pm SD $(p<0.05)$

\section{DISCUSSION}

Breast cancer is one of the deadly cancers, and is responsible for significant mortality in women across the globe [16]. The treatment for breast cancer is obstructed by late diagnosis due to unavailability of reliable biomarkers and efficient therapeutic targets [14]. MicroRNAs are important biomarkers and therapeutic targets for the diagnosis and treatment of several cancers 
[17]. Since miRNAs are involved in a number of cellular and physiological processes, their expression is often affected in disease conditions. Consistently, the expressions of several miRNAs are often deregulated in cancer cells [18].
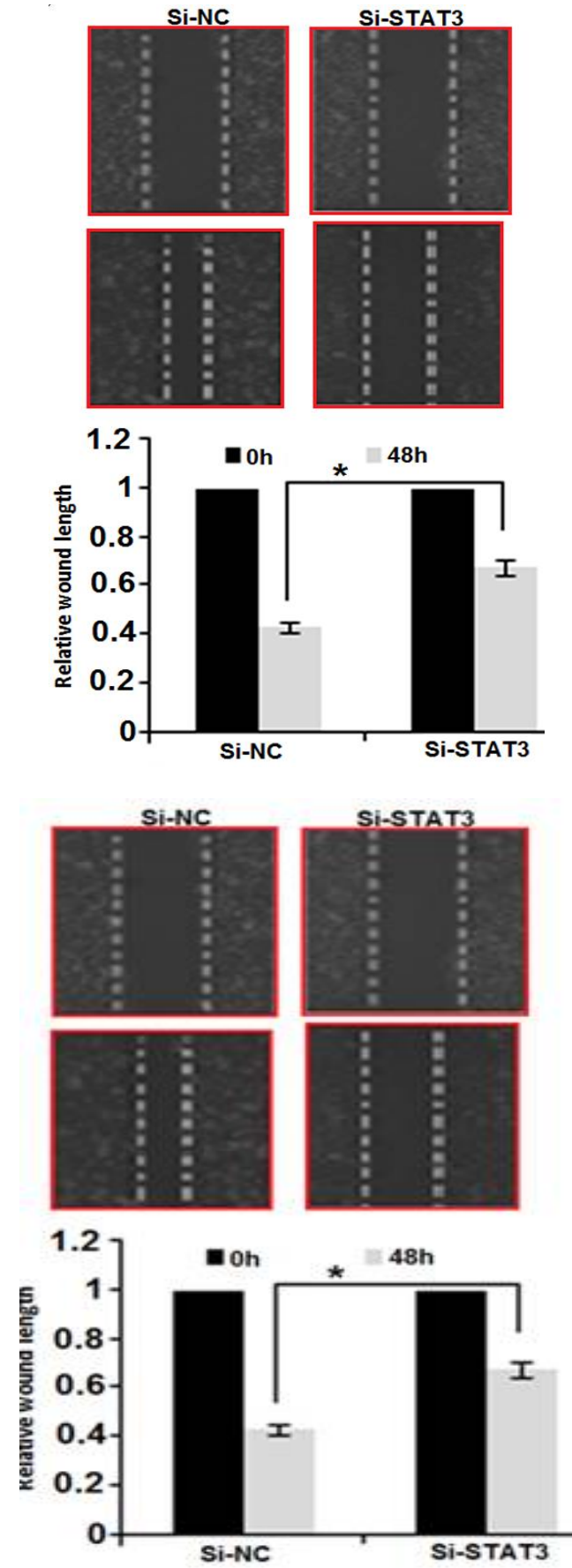

Figure 6: Suppression of miR-9 inhibited the migration of SK-BR-3 breast cancer cells. The experiments were carried out in triplicate. Data are expressed as mean \pm SD $(p<0.05)$

In the present study, it was observed that the expression of miR-9 was significantly down- regulated in cancer cells. Previous studies have also reported that miR-9 is downregulated in cancer cells. For instance, it has been shown that miR-9 is significantly downregulated in oral squamous carcinoma cells, and that it regulates cell migration and invasion [19]. Similarly, miR-9 is suppressed in glioblastoma cells, and that it promotes their proliferation and tumorigenesis [20]. In the present study, in order to investigate the role of miRNA, miRNA-9 was overexpressed in breast cancer cells. The results indicated that overexpression of miR-9 in breast cancer cells inhibited their proliferation and colony formation potential. MiR-9 overexpression in breast cancer cells also suppressed their cell migration and motility. These results are well supported by studies carried out earlier. For example, miR-9 has been reported to inhibit the migration and invasion of gastric cancer cells [21]. In yet another study, it was shown that miR-9 regulated the proliferation and metastasis of liver cancer cells [20]. MicroRNAs exert their effects by regulating the expression of human genes. Indeed, about thirty human genes are regulated by miRNAs [22]. TargetScan analysis of miR-9 revealed that miR-9 targets STAT3 in breast cancer cells. STAT proteins have been previously shown to regulate proliferation and tumorigenesis in different types of cancers [23]. It was observed in the present study that the expression of STAT3 was upregulated in all the breast cancer cell lines used, and miR-9 overexpression in breast cancer cells also caused downregulation of STAT3 expression in SK-BR-3 cells. Furthermore, silencing of STAT3 had effects on proliferation and migration of breast cancer cells similar to those of miR- 9 overexpression. Thus, MiR-9 may be an important therapeutic target for breast cancer.

\section{CONCLUSION}

The findings of this study show that miR-9 is significantly downregulated in breast cancer cell lines, and that overexpression of miR-9 inhibits the proliferation and migration by targeting STAT3. Therefore, miR-9 is likely to be an important therapeutic target for the management of breast cancer.

\section{DECLARATIONS}

\section{Acknowledgement}

We thank Affiliated Weihai Second Municipal Hospital of Qingdao University for supporting this study. 


\section{Conflict of interest}

No conflict of interest is associated with this work.

\section{Contribution of authors}

We declare that this work was done by the authors named in this article and all liabilities pertaining to claims relating to the content of this article will be borne by the authors. This study was performed by Yan Zhang under the supervision of Guangquan Dai. Yan Zhang did all the studies, Guangquan Dai designed the whole experiments.

\section{REFERENCES}

1. DeSantis CE, Ma J, Goding Sauer A, Newman LA, Jemal A. Breast cancer statistics, 2017, racial disparity in mortality by state. CA Cancer J Clin. 2017; 67(6): 439448.

2. Mariotto $A B$, Etzioni R, Hurlbert M, Penberthy L, Mayer M. Estimation of the number of women living with metastatic breast cancer in the United States. Cancer Epidemiol Biomarkers Prev. 2017; 18: 11-15.

3. Zheng J, Tabung FK, Zhang J, Liese AD, Shivappa $N$, Ockene JK, Caan B, Kroenke CH, Hébert JR, Steck SE. Association between post-cancer diagnosis dietary inflammatory potential and mortality among invasive breast cancer survivors in the Women's Health Initiative. Cancer Epidemiol Biomarkers Prev. 2018; 22: 4-9.

4. Ramassone $A$, Pagotto $S$, Veronese $A$, Visone $R$. Epigenetics and MicroRNAs in cancer. Int $J$ Mol Sci. 2018; 19(2): 459-463.

5. Ji $W$, Sun $B$, Su C. Targeting microRNAs in cancer gene therapy. Genes. 2017; 8(1):21-26.

6. Hu B, Sun M, Liu J. MicroRNA 204 suppressed proliferation and motility capacity of human hepatocellular carcinoma via directly targeting zinc finger $E$ box binding homeobox 2. Oncol Lett. 2017; 13(5): 3823-3830.

7. Wu G, Wang J, Chen G, Zhao X. microRNA-204 modulates chemosensitivity and apoptosis of prostate cancer cells by targeting zinc-finger E-box-binding homeobox 1 (ZEB1). Am Jl Trans Res., 2017; 9(8): 3599-3602.

8. Canu V, Sacconi A, Lorenzon L, Biagioni F, Sardo FL, Diodoro MG, Muti P, Garofalo A, Strano S, D'Errico A, Grazi GL. MiR-204 down-regulation elicited perturbation of a gene target signature common to human cholangiocarcinoma and gastric cancer. Oncotarget. 2017; 8(18): 29540-29544.

9. Han Z, Zhang $Y$, Sun $Y$, Chen J, Chang $C$, Wang $X$, Yeh S. ERß-mediated alteration of circATP2B1 and miR-204$3 p$ signaling promotes invasion of clear cell renal cell carcinoma. Can Res. 2018; 1: 7-12.
10. Song Y, Li J, Zhu Y, Dai Y.MicroRNA-9 promotes tumor metastasis via repressing $E$-cadherin in esophageal squamous cell carcinoma. Oncotarget. 2014; 5(22): 11669-11673.

11. Zhang J, Jia J, Zhao L, Li X, Xie Q, Chen X, Wang J, Lu F. Down-regulation of microRNA-9 leads to activation of IL-6/Jak/STAT3 pathway through directly targeting IL-6 in HeLa cell. Mol Carcino. 2016; 55(5): 732-742.

12. Troiani $T$, Napolitano $S$, Vitagliano D. Primary and acquired resistance of colorectal cancer cells to antiEGFR antibodies converge on MEK/ERK pathway activation and can be overcome by combined MEK/EGFR inhibition. Clin Cancer Res, 2014; 20(14): 3775-3786.

13. Mosmann T. Rapid colorimetric assay for cellular growth and survival: application to proliferation and cytotoxicity assays. J Immunol Methods, 1983; 65: 55-63.

14. Lee YH, Cheng FY, Chiu HW. Cytotoxicity, oxidative stress, apoptosis and the autophagic effects of silver nanoparticles in mouse embryonic fibroblasts. Biomaterials, 2014; 35(16): 4706-4715.

15. Lyons $A B$, Parish $C R$. Determination of lymphocyte division by flow cytometry. J Immunoll Meth. 1994; 171(1): 131-137.

16. DeSantis CE, Ma J, Goding Sauer A, Newman LA, Jemal A. Breast cancer statistics, 2013. CA Cancer J Clin. . 2014; 64(1): 52-62.

17. Inoue $M$, Nakagomi $H$, Nakada $H$. Specific sites of metastases in invasive lobular carcinoma: a retrospective cohort study of metastatic breast cancer. Breast Cancer, 2017; 24(5): 667-672.

18. Shah $M Y$, Ferrajoli A, Sood AK. MicroRNA therapeutics in cancer-an emerging concept. EBio Medicine. 2016; 12: 34-42.

19. Di Leva G, Garofalo M, Croce CM. MicroRNAs in cancer. Annu. Rev. Pathol.-Mech. Dis. 2014; 9: 287-314.

20. $Y u$ T, Liu $K$, Wu Y, Fan J.MicroRNA-9 inhibits the proliferation of oral squamous cell carcinoma cells by suppressing expression of CXCR4 via the Wnt/ $\beta$-catenin signaling pathway. Oncogene. 2014; 33(42): 5017-5022.

21. Gomez GG, Volinia S, Croce CM.: Suppression of microRNA-9 by mutant EGFR signaling upregulates FOXP1 to enhance glioblastoma tumorigenicity. Canr Res. 2014; 74(5): 1429-1439.

22. Zheng L, Qi T, Yang D. microRNA-9 suppresses the proliferation, invasion and metastasis of gastric cancer cells through targeting cyclin D1 and Ets1. PloS one, 2013; 8(1): e55719.

23. Hao-Xiang $T$, Qian $W$, Lian-Zhou C. MicroRNA-9 reduces cell invasion and E-cadherin secretion in $S K$ Hep-1 cell. Med Oncol. 2010; 27(3): 654-60.

24. He L, Hannon GJ. MicroRNAs: small RNAs with a big role in gene regulation. Nat Rev Genet. 2004; 5(7): 522525.

25. Yue $P$, Turkson J. Targeting STAT3 in cancer: how successful are we? Expert Opin Investig Drugs. 2009; 18(1): 45-56. 